\title{
The IT Revolution: Applications and Strategies for Transgeographic Learning and Academia in the Twenty-First Century
}

\author{
Dr. Nicole A. Buzzetto-More \\ University of Maryland Eastern Shore, Princess Anne, MD USA
}

Nabuzzetto-more@umes.edu

\begin{abstract}
Digital technologies are closing spatial and temporal gaps while engendering expansive new international communities. Replete with symbolic interactions, these transgeographic communities inspire new realms of educational possibility, allowing educators and learners to broaden perspectives through intellectual discourse and collaboration while eradicating cultural divides.

The Summer Ecosystems Experience for Undergraduates (SEE-U) is a superior model of how such technology can be used to this end. Available to colleges and university students worldwide, the SEE-U program operates at three geographically distinct locations concurrently. The program includes global networking, GPS and GIS usage, real-time interactions, data collection, a globally networked geo-referenced digital database that was specifically created for this project, data manipulation, online lectures, bulletin board discussions, Web-based office hours, links to relevant resources, expert presenters, online demonstration videos, networked simulations, collaborative research, and a series of student presentations.
\end{abstract}

Keywords: Information Communication, e-Learning, Co-operative Learning, Global Education, Distance Education, Global Networking, Instructional Technology

\section{Introduction}

The field of education has traditionally been classroom-oriented, involving a teacher who lectures students and students who are evaluated according to their ability to regurgitate memorized information. Technology is helping to change that model radically in terms of the way we perceive teaching and learning.

When information technologies are used in education they enhance presentations, communications, collaborations, curricula delivery; allow for greater flexibility in assessment; increase the wealth and availability of resources; and foster global education projects.

The current impact of technological innovation extends farther and deeper than at any other time in our history. These advances have altered the very constructs of space and time and have changed visibility, making it global in scope. In other words, advances have decreased the time

Material published as part of these proceedings, either on-line or in print, is copyrighted by Informing Science. Permission to make digital or paper copy of part or all of these works for personal or classroom use is granted without fee provided that the copies are not made or distributed for profit or commercial advantage AND that copies 1) bear this notice in full and 2) give the full citation on the first page. It is permissible to abstract these works so long as credit is given. To copy in all other cases or to republish or to post on a server or to redistribute to lists requires specific permission from the publisher at Publisher@InformingScience.org that it takes to transmit information while increasing the distances it can be sent, as well as the potential audience. As the time to transmit mediated information abbreviates, and as the audience receiving it becomes increasingly diversified, the result is a reconstruction of the concepts of proximity, 
moving us ever onward toward a shared global community. We now have reached a point in our technological evolution in which media convergence and global networking give the illusion that a person sitting in front of a computer halfway around the world is in essence just a split second away. By shifting the importance of the campus as the primary nucleus of intellectual discourse, interactions and collaborations among learners regardless of space and time are rapidly becoming increasingly commonplace (McClintock, 1999).

Digital technologies are closing spatial and temporal gaps while engendering a growing number of international communities. These communities open up a world of educational possibilities replete with symbolic interactions that cross geographic borders. Through well-developed globally networked technologies, educators and learners worldwide interact in courses and projects that cross cultural divides, encourage collaboration, develop broader perspectives, and foster intellectual discourse. Research indicates that the use of information technologies in the fostering of global education is a highly effective means for encouraging educational empowerment (McIsaac, 1993).

Numerous research studies have shown that people learn through meaningful interactions with others (Johnson \& Thomas, 1994). Relevant discourse is at the center of these interactions; as a result, the social construction model uses discourse and debate to encourage thought, idea formation, evaluation, and expression. Community-centered learning environments build on the social construction model, in which learning is dependent on academic partnerships that use discussion and collaboration, making knowledge an individual acquisition dependent on social interactions. A major goal of global education is the creation of learning communities that include meaningful discourse between and among cultures.

Examination has shown that networked digital technologies are the most efficient and costeffective means of creating scholarly environments based on global education (McIsaac, 1993). The benefits of technology-facilitated global education include: increased exposure to, and understanding of, different cultures so as to combat ethnocentrism; opportunities to prepare learners to enter what is increasingly a global workforce; the fostering of intercultural communications skills; the offering of unique insights through exposure to global perspectives; the development of the preparedness skills that facilitate student collaboration; and the building of necessary technological skills.

Technology and global-education partnerships can provide students with nontraditional learning experiences and perhaps no subject matter is better suited for technology incorporation then science education. In the area of science education, the goal is to take science learning away from the pre-packaged lab and decontextualized textbook-based lessons and transform science education by linking science education to scientific practice. Bridging the gaps between learners and scientists is done through the use of real data, hands-on experimentation, the examination of working systems, modeling, and access to actual working scientists.

Digital technologies are allowing for more creative and innovative science education that goes beyond the traditional drill and memorization of facts. The study of science deals with complex, multifaceted phenomena. Technology facilitates the study of science by increasing the scope of available resources, allowing for expedient and reliable access to data and research materials, enhancing collaborations, encouraging systems thinking, and by effectively delivering curricula (Scalpeter, 1998). Technology helps students imitate the method of inquiry practiced by actual working scientists (Kastens, 1999).

Numerous studies have shown that well developed technologies enhance science education. Visual mapping technologies have been found to help students build effective mental models (Black \& Kaplan, 2001). Evidence has supported that digital learning tools enhance student development of scientific reasoning skills (Black, Hachey, \& Tsuei, 2001). The use of technology facilitated 
multi-user learning environments that immerse students in the scientific process help build deep understandings of complex scientific knowledge and enhance student motivation in learning science (Dede, n.d.; Dede, Ash, Loftin \& Salzman, 2000).

When information communication is used to create global education, it can include a multitude of technologies. Requisite, however, is that the technology is networked; well developed and educationally relevant following student-centered design principles; that it be tested prior to implementation; contain a discussion section and a shared workspace; is user-friendly; includes easily accessible technology support; and has a backup plan in the event of technology failure.

In order for technology-facilitated global learning experiences to be successful, they should include a central question for investigation; a shared online learning platform; a clear understanding of purpose; extensive student and instructor preparedness for technology usage; interaction with professional experts; a discussion forum; and a collaborative project that is shared among participants.

The Summer Ecosystems Experience for Undergraduates, otherwise known as SEE-U, is a superior example and model of the how information technologies can be used to foster global education. Under the auspices of Columbia University's Center for Environmental Research and Education, CERC, an organization comprised of world-class scientific institutions. It was created through a collaboration with the Columbia Center for New Media in Teaching and Learning, an instructional technology- development center housed at Columbia University; the Center for International Earth Sciences Information Network, an organization that seeks to use information technology to enhance the worldwide effort to examine the impact of humans on the environment; and the Black Rock Forest Consortium, a unique and powerful amalgamation of distinguished academic institutions and science and cultural centers that successfully collaborate to enhance scientific research and education.

\section{Discussion}

The five-week SEE-U course is offered to students enrolled in colleges and universities throughout the world. It is a total immersion course promoting anchored instruction held at several locations simultaneously, including the Black Rock Forest in New York State, the Atlantic Forest in Brazil, and Punta Cana in the Dominican Republic, with plans to expand to Kenya.

The course focuses on environmental education where participating students concentrate on the examination of one biome but make comparisons with and learn about other biomes. The learners explore biomes globally and locally, developing an understanding of population ecology, biotic and abiotic processes, community ecology, conservation, pollution and habitat fragmentation.

Eligibility is available to undergraduate students across the globe, regardless of major, provided they are interested in participating in a global learning experience. Interested students visit the SEE-U website, found at http://www.columbia.edu/itc/cerc/seeu. From the website students can request information or download applications. The website also includes the program's curriculum, field site information, and slide shows. The students select their field sites and choose to enroll either of the two summer sessions.

Scientists rarely work independently or in isolation from other scientists. As a result, participants in the SEE-U program conduct scientific research and make discoveries in cooperative learning groups and participate in program-wide research projects shared among all participants. The learners create presentations that result in their sharing of findings and entering into discourse with students located remotely. Because success for the students is largely dependent on collaboration, learners develop an understanding that science is in and of itself a collaborative practice. 
SEE-U involves a technology-facilitated curriculum, which requires the students take part in, and implement the scientific method. The novel technology-enhanced aspects of the SEE-U program include global networking, GPS/GIS training, electronic discussions, data collection, data manipulation, online lectures, bulletin board discussions, instructors offering online office hours, remotely located expert presenters, links provided to relevant resources, online demonstration videos, networked simulations, and the completion of collaborative as well as an independent research projects.

The students begin with background information and an initial question for investigation. Throughout the course they investigate the question by gathering data and testing out different hypotheses in the same manner as actual working scientists. The hands-on experimental aspect of the SEE-U course helps the students to develop and build scientific research skills.

The SEE-U curriculum comprises four major sections, namely, biomes, biotic processes, abiotic processes, and contemporary issues. Biomes covers the understanding of the world's major biomes, the different biomes represented by the participating field sites, and provides an in-depth focus on the local biome where the students are immersed. The section on biotic processes includes natural selection and evolution; growth and competition, otherwise known as population dynamics; community ecology; and the basis of ecosystems. Abiotic processes covers the role of light and temperature, geology and soils, chemical and hydrological cycles, and geological disturbances. Contemporary issues studies the social, political, and ethical issues that are of concern to their respective biome as well as to the other field sites.

Within each section, topics are broken down into modules. In total there are 16 modules, each taking one or two days to cover. The learning modules include experiments, and throughout the five-week course the learners participate in roughly 20 experiments. During the experiments, learners enter the field and collect data, later conducting simulations and modeling to analyze their findings. Students work with both archived and new data - seeking, analyzing, and learning from networked information - presenting the total of their work.

Most educational theorists agree that intellectual discussion facilitates learning. The learners in the SEE-U program have symbolic interactions with their counterparts located at the remote field sites. Throughout the program they enter into relevant discourse as they participate in online discussions, take part in collaborative research, share and compare findings, conduct networked simulations, and hear and participate in lectures and discussions given by scientists across the globe.

Since its inception in the summer of 2000, the SEE-U program has attracted students around the world. It involves both an in-depth field and technology-based introduction to ecology, and environmental studies and digital technologies are used throughout the course to help students explore, gather, analyze, visualize, and compare data.

SEE-U is dependent on and uses technology in interesting and innovative ways serving as an example for other courses. The program uses technology in the acquisition, analysis, modeling, and comparison of data but also to foster communications, collaborations, discussions, debate, the delivery of curricula, and further research. Students participating in the SEE-U program take advantage of Geographic Position System (GPS) technology to spatially reference data; Geographic Information System (GIS) technology to allow detailed mapping and topographical representation of data; modeling software for the visualization of and experimentation with data; detailed computer networking; online research; digital lectures and demonstration videos; synchronous and asynchronous discussions with students across geographic borders; and advanced database technology that is multi-queriable, including metadata information. 
Although the SEE-U program is a total immersion course, it is designed and delivered in many ways as a distance-learning course. Course information is completely delivered online, including lecture notes, slides, text, video, web links, database access, discussion-board availability, live chats, and subscriptions to relevant online scientific publications. Among the benefits of the online delivery of information are increased access to materials, accuracy in delivery, and the ability for students to visit and revisit course information according to need and interest.

Global networking allows the learners to communicate and collaborate across all of the program's biological field sites as students share data and work on research projects together. As a result, this course helps illustrate the global nature of the scientific community and the importance of sharing and comparing discoveries with other scientists.

At the core of the Summer Ecosystems Experience is the use of EBiome, which is a geo-spatially referenced database that is available through the global network to all program participants. During the program, participants embark to the field and collect data using GIS instrumentation, bringing it back to headquarters where the data is entered into the EBiome database. Datasets in EBiome can be reference and compared spatially, topically, or by biome. Students participating in the SEE-U program compare their data to archival data and to data collected by their counterparts at the remote field sites. The students discuss information across locations as they enter into relevant discourse through interactions with learners via the global network at the other biological field sites.

EBiome is a unique digital database that is designed to serve as a central repository to what is increasingly becoming significant and copious amounts of longitudinal data. EBiome was created specifically for the SEE-U program and is one of the most unique and integral parts of the course. EBiome was created by the Center for Environmental Research and Conservation (CERC), the Columbia Center for New Media in Teaching and Learning (CCNMTL), and the Center for International Earth Sciences Information Network (CIESEN).

All of the data collected as part of the student investigations is entered into EBiome and can be accessed by all who are participating in the program onsite or remotely, as well as by instructors and research scientists the world over. The database is designed to encourage data comparison so that learners can examine the differences of processes across biomes. At the same time, the students are given the opportunity to assist some of the world's leading scientists in their efforts.

When field data is collected by students, Global Positioning technology is used. GPS technology involves the use of radio signals received from at least four satellites that exist in geosynchronous orbits circling the Earth. GPS makes it possible to pinpoint exact locations where data is collected. Student use the GPS system to determine the precise latitude and longitude where data are collected. Upon returning to base station the students input their data into the specially designed EBiome database.

Students enrolled in the SEE-U course are well versed in the use of Ebiome. Prior to working with the technology, students are trained in its proper use and many features. This training is built directly into the course curriculum.

Ebiome is a versatile and multidimensional database that allows users to query information in numerous ways and across sites. For example, users may search data-sets by any number of characteristics such as data type, by spatial reference, and or by the date or time of the data collection. Users can set parameters for querying data such as soil $\mathrm{ph}>6.4<3.2$. Additionally, Ebiome includes copious amounts of metadata elements, which help to insure data accuracy and integrity and allow for additional forms of inquiry. According to CERC the benefits of Ebiome are the storage of data for longitudinal study and comparison, the referencing of data and compilation in 
a digital repository, the geo-referencing of data, the amount of metadata included, and that students take part in the data-collection process.

Ebiome allows data to be represented spatially, using Geographic Information System (GIS) technology. Research studies have shown that visual mapping programs such as GIS have been shown to help learners build effective mental models (Black and Kaplan, 2001). GIS is a dynamic mapping system that allows individuals to collect, manage, and spatially reference volumes of data. GIS involves a series of aerial photos that have been digitized allowing for the construction of elevation models. Additional information is later entered on roads, trails, streams, landmarks, and other features that may not be included in aerial photos. Information displayed in GIS involves the overlaying of maps where individual map layers represent geological characteristics.

The GIS program used by SEE-U was specifically designed and formatted for use by SEE-U. For this project, the information is accessible using the ESRI Arc View Software. The Trimble GeoExplorer mapping system is the field receiver that accepts the GPS information. The Trimble GeoExplorer and the ESRI Arc View software allow individuals to quickly learn how to collect, enter, and correct, and map data.

One of the goals of SEE-U is to help introduce students to scientific practice. According to CERC, when students complete the SEE-U curriculum, they have developed a mastery of several key concepts, including, an understanding of the scientific method and its underlying theory; knowledge of the multilevel interaction of ecological elements and an appreciation of the importance of not disturbing these relationships; an understanding of the human impact on the environment; insight on the interaction of the world's biomes; illustration of ecological and biological diversity; comprehension of population dynamics; knowledge of the chemical cycle within an ecosystem; the ability to work with cutting-edge scientific research technology; an appreciation for human conservation, mediation, and preservation efforts; an appreciation for the global nature of scientific work; and the ability to collaborate and enter into relevant discourse with scientists across the globe.

Not only is the SEE-U program concerned with building knowledge, it is also designed to help students learn several key skills. According to CERC, these skills are a cornerstone of being a successful science student and later in a career as a professional working scientist. They include the ability to implement the scientific method and incorporate it into meaningful experiments; understanding primary statistical methodologies and the ability to conduct and select appropriate simple statistical analyses; knowledge of different field and laboratory techniques; the ability to gather data from a wide variety of sources and determine the relevance of that data; aptitude in preparing and presenting logical oral and written scientific research reports; the understanding of the importance of and the use of technological instrumentation to enhance scientific research; and the ability to communicate and collaborate with scientists across geographic divides.

\section{Conclusion}

Digital technologies are closing spatial and temporal gaps while engendering expansive new international communities. Replete with symbolic interactions, these transgeographic communities inspire new realms of educational possibility, allowing educators and learners to broaden perspectives through intellectual discourse and collaboration while eradicating cultural divides.

The Summer Ecosystems Experience for Undergraduates (SEE-U) is a superior model of how such technology can be used to this end. Available to colleges and university students worldwide, the SEE-U program operates at three geographically distinct locations concurrently. The program includes global networking, GPS and GIS usage, real-time interactions, data collection, a globally networked geo-referenced digital database that was specifically created for this project, data ma- 
nipulation, online lectures, bulletin board discussions, Web-based office hours, links to relevant resources, expert presenters, online demonstration videos, networked simulations, collaborative research, and a series of student presentations.

The activities included in the SEE-U program have been designed to bridge the gaps between scientific practice and learning and to prepare the next generation of scientists to use cutting edge technologies, be active in global discourse, and collaborate with fellow scientists. As a result of its design, the SEE-U program provides a unique experience that is unparalleled in field-science education.

Although the SEE-U project focuses on global education in the area of science, the program has much broader implications across disciplines. There are numerous subjects and methodologies that can be employed in the use of networked digital technologies to create global learning communities, what is crucial is that certain characteristics are included and certain issues addressed. The factors to be addressed include issues of language; pedagogy; technological accessibility, usability and reliability; motivation; and project cost and practicality (McIsaac, 1993). The characteristics that are important to the successful use of information technologies as a means to encourage global education are willing and prepared instructors, exemplary curricula, welldeveloped technologies, a globally networked and shared-learning platform, and extensive opportunities for intellectual discourse.

\section{References}

Black, J. \& Kaplan, K. (2001). Computer-based tools for the development and investigation of scientific reasoning skills. In Montgomerie, C. \& Vitelli, J. (Eds.).Proceedings of EdMedia world conference on educational multimedia, hypermedia \& telecommunications. Norfolk, VA: Association for the Advancement of Computing in Education.

Black, J., Hachey, A., \& Tsuei, L. (2001). Fostering mental-model thinking during design. In Montgomerie, C. \& Vitelli, J. (Eds.). Proceedings of EdMedia world conference on educational multimedia, hypermedia \& telecommunications. Norfolk, VA: Association for the Advancement of Computing in Education.

Buzzetto-More, N. (2004). The Black Rock Forest consortium: A narrative. Ed.D. dissertation, Columbia University, New York.

Darling-Hammond, L. (1997). The right to learn: A blueprint for creating schools that work. Hoboken, NJ: Jossey Bass

Dede, C. (n.d.). Museum related multimedia and virtual learning environments for teaching and learning science. NSF funded research on multi-user virtual learning environments. Paper retrieved August 2003, from: http://www.virtual.gmu.edu/EDIT611/projdspt.pdf

Dede, C., Ash, K., M. Loftin, B., \& Salzman. (2000). In M. Jackobson \& R. Kozma, Innovations in science and mathematics education: Advanced designs for technologies of learning. Mahwah, NJ: Lawrence Erlbaum Associates.

Frederiksen, J. \& White, B. (2000). In: Jackobson, M. \& R. Kozma, Innovations in science and mathematics education: Advanced designs for technologies of learning. Mahwah, NJ: Lawrence Erlbaum Associates.

Heterick, R.C., Jr., Mingle, J. R., \& Twigg, C. A. (1997). The public policy implications of a global learning infrastructure. Paper retrieved August 2003, from http://www.educause.edu/nlii/keydocs/policy.html

Johnson, S. D., \& Thomas, R. G. (1994, Winter-Spring). Implications of cognitive science for instructional design in technology education. Journal of Technology Studies, 20, 33-45. (EJ 494 218) 
Kastens, K. (1999, March 3). Adding real-time data to the Black Rock Forest digital library to enable students to engage in predictiveiInvestigations. Unpublished Proposal to the National Science Foundation. New York, NY: Columbia University, Lamont Doherty Earth Observatory.

McIssac, M. (1993, January). The global classroom: An international perspective. In: Proceedings of selected research and developement presentations at the convention of the Association for Educational Communications and Technology Education. Educational Resources Information Center. ERIC Identifier: ED3262186

McClintock, R. (1999). Educators manifesto: renewing the progressive bond with posterity through the social construction of digital learning communities. Published Paper. New York, NY: Teachers College, Columbia University, Institute for Learning Technologies.

Scalpeter, J. (1998). Interview with Cheryl Lemke. Ed Tech Research Forum. Technology and Learning Magazine.

Vygotsky. (1978). Mind in society: the development of higher psychological processes. Cambridge, MA: Harvard University Press.

\section{Biography}

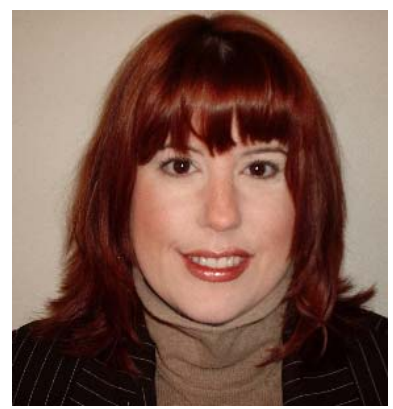

Dr. Nicole A Buzzetto-More has a doctorate in communications and instructional technology from Columbia University, a masters in education from Columbia University, a masters of science in communications from the College of New Rochelle, and a bachelor of arts degree with a double major in communications and studio art from Marist College. Originally from New York, she currently resides on the eastern shore of Maryland where she is a faculty member at the University of Maryland Eastern Shore. Her intellectual interests include the uses of digital technologies to augment teaching and learning. Dr. BuzzettoMore is married and has two children. She spends her free time with her husband, Robert, and two small boys, Ryan and Anthony. 